$\begin{aligned} \text { Artvin Çoruh Üniversitesi } & \begin{array}{l}\text { Artvin Coruh University } \\ \text { Orman Fakültesi Dergisi } \\ \text { Journal of Forestry Faculty }\end{array} \\ \text { ISSN:2146-1880, e-ISSN: 2146-698X } & \text { ISSN:2146-1880, e-ISSN: 2146-698X } \\ \text { YII: 2021, Cilt: 22, SayI:1, Sayfa: 9-18 } & \text { Year: 2021, Vol: 22, Issue:1, Pages: 9-18 } \\ & \text { ofd.artvin.edu.tr }\end{aligned}$

\title{
Hatay (Türkiye) ilinin bazı doğal ve kültürel sit alanları florası üzerine bir çalışma
}

\section{A study on the flora of some natural and cultural sites of Hatay province (Turkey)}

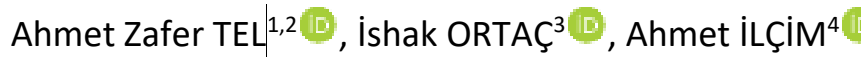 \\ ${ }^{1}$ Iğdır Üniversitesi, Ziraat Fakültesi, Tarımsal Biyoteknoloji Bölümü Iğdır, Türkiye \\ ${ }^{2}$ Adıyaman Üniversitesi, Fen Edebiyat Fakültesi, Biyoloji Bölümü, Adıyaman, Türkiye \\ ${ }^{2}$ Adıyaman Üniversitesi, Fen Bilimleri Enstitüsü, Biyoloji Anabilim Dalı, Adıyaman, Türkiye \\ ${ }^{3}$ Hatay Mustafa Kemal Üniversitesi, Fen Edebiyat Fakültesi, Biyoloji Bölümü, Hatay, Türkiye
}

\section{Eser Bilgisi / Article Info}

Araştırma makalesi / Research article

DOI: 10.17474/artvinofd.757027

Sorumlu yazar / Corresponding author İshak Ortaç

e-mail: orto_19891989@yahoo.com.tr

Geliş tarihi / Received

01.07.2020

Düzeltme tarihi / Received in revised form

06.11.2020

Kabul Tarihi / Accepted

23.11.2020

Elektronik erişim / Online available

12.05.2021

\section{Anahtar kelimeler:}

Korunan alanlar

Bitki envanteri

Antakya

Hatay

Flora

Türkiye

\section{Keywords:}

Protected areas

Plant inventory

Antakya

Hatay

Flora

Turkey

\section{Özet}

Bu araştırma 2015-2016 yılları arasında Hatay ilinde bulunan; Erzin Doğal Sit Alanı, Gölbaşı Gölü, Habib-i Neccar Dağı ve Antakya Kalesi, Saint Pierre Kilisesi ve Harabeleri, Harbiye Şelaleleri ve Yenişehir Gölü çalışma alanlarını kapsamaktadır. Araştırma sonucunda 52 familyaya ait, 129 cins, 108 tür, 25 alttür ve 22 varyete olmak üzere, toplam 155 takson belirlenmiştir. Araştırma alanında belirlenen taksonlardan 7 tanesi endemik olup, endemizm oranı \%4.5'dir. Çalışma alanında belirlenen taksonların fitocoğrafik bölgelere dağılımı şu şekildedir; Akdeniz (Doğu Akdeniz dâhil) 57 takson (\%36.8), İranTuran 7 takson (\%4.5), Avrupa-Sibirya 6 takson (\%3.9), geniş yayılışlı 37 takson (\%23.9) ve bilinmeyen 48 (\%30.9) taksondur. Çalışma alanında takson sayısı bakımından en büyük familyalar Fabaceae (22), Lamiaceae (15), Asteraceae (13) ve Liliaceae (9)' dir. Çalışma alanında takson sayısı bakımından en büyük cinsler Vicia (4), Silene (3), Stachys (3), Quercus (3), Salvia (3) ve Muscari (3)'dir.

\begin{abstract}
This research was conducted between 2015-2016. Study areas are; Erzin Natural Protected Area, Gölbaşı Lake, Habib-i Neccar Mountain and Antakya Castle, Saint Pierre Church and Harebs, the Harbiye Waterfalls and Yenişehir Lake located in Hatay province (Turkey). As a result of the research, 155 taxa belonging to 52 families, 129 genera, 108 species, 25 subspecies and 22 varieties were determined. 7 taxa identified in the research area are endemic and the rate of endemism is $4.5 \%$. The distribution of taxa determined in the study area to phytogeographical regions is as follows; Mediterranean (including Eastern Mediterranean) 57 taxa (36.8\%), Iran-Turan 7 taxa (4.5\%), EuroSiberian 6 taxa (3.9\%), 37 widespread taxa (23.9\%) and $48(30.9 \%)$ unknown taxa. Fabaceae (22), Lamiaceae (15), Asteraceae (13) and Liliaceae (9) are the largest families in terms of taxa's numbers in the study area. Vicia (4), Silene (3), Stachys (3), Quercus (3), Salvia (3) and Muscari (3) are the largest genera in terms of taxa's number in the study area.
\end{abstract}

\section{Giriş}

Türkiye dünya üzerinde $36^{\circ}-42^{\circ}$ Kuzey enlemleri ile $26^{\circ}$

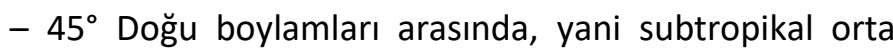
kuşakta bulunmaktadır. Ayrıca üç tarafı denizlerle çevrili bir kara parçasıdır. Kıyı kesimlerinde ılıman iklim tipleri görülmekteyken, yurdumuzun batısından doğusuna doğru gidildikçe ortalama yükselti artmakta ve denizel etkiden uzaklaşılmasından dolayı da iklim koşulları sertleşip karasallaşmaktadır. Yurdumuzda coğrafik yapının, topoğrafik yapının, jeolojik yapının ve farklı iklim tiplerinin etkisiyle flora oldukça zenginleşmiştir. Bu sebepten farklı fitocoğrafik bölgelere ait elementlerin ve endemik bitki türlerinin sayısı oldukça fazladır (Çevre ve Şehircilik Bakanlığı 2016).

Türkiye de toplam vasküler takson sayısı 12.006 'dır. Bu sayıya 233 yabancı kökenli (alien) ve kültür bitkisi dâhildir. Endemik takson sayısı ise $3.778^{\prime}$ dir. Floradaki endemizm oranı ise \%31'dir (Erik ve Tarikahya 2004).

Çalışma alanına yakın bölgelerde benzer florostik çalışmalar yapılmıştır. Bu çalışmalar; Kuseyr (Habib-in Neccar) Dağları (Yolcu 1998) adlı çalışmada 60 familyaya ait 162 cins, 253 takson belirlenmiştir. Belirlenen taksonlardan 14 tanesi endemik olup endemizm oranı 
\%5.6'dır. The Flora of Dörtyol and Erzin Districts (Türkmen ve Düzenli 1998) adlı çalışmada 98 familyaya ait 328 cins, 629 takson belirlenmiştir. Belirlenen taksonlardan 47 tanesi endemik olup endemizm oranı \%7.5'dir. Musa Dağı (Düzenli ve Çakan 2001) adlı çalışmada 87 familyaya ait 287 cins, 522 takson belirlenmiştir. Belirlenen taksonlardan 52 tanesi endemik olup endemizm oranı \%9.3'dür.Samandağ (Hatay) Kıyı Kumulları (Kayıkçı 2006) adlı çalışmada 48 familyaya ait 152 cins, 198 takson belirlenmiş̧ir. Tübives (Türkiye Bitkileri Veri Servisi) (Tübives 2020) verilerine göre Hatay ilinde toplam 1304 takson belirlenmiştir. Belirlenen bu taksonlardan 183 tanesi endemik olup endemizm oranı \%14.03'dür.

Bu çalışma T.C. Çevre ve Şehircilik Bakanlığı'nın“Adana, Hatay, Mersin, Kahramanmaraş, Osmaniye, Gaziantep ve Kilis illeri Doğal Sit Alanlarının Ekolojik Temelli Bilimsel Araştırma Projesi" (Proje No: 2014/151078) kapsamında yapılmıştır. Hatay ilinde bulunan Erzin Doğal Sit Alanı, Gölbaşı Gölü, Habib-i Neccar Dağı ve Antakya Kalesi, Saint Pierre Kilisesi ve Harabeleri, Harbiye Şelaleleri ve Yenişehir Gölü'ne yapılan arazi gezilerinde elde edilen verilerin sunumu yapılarak alanların floristik yapısına katkı sağlamak amaçlanmıştır.

\section{MATERYAL ve YÖNTEM}

Araştırma alanının materyalini 2015-2016 yılları arasında Hatay ilinde bulunan 6 farklı noktadan; Erzin Doğal Sit Alanı, Gölbaşı Gölü, Habib-i Neccar Dağı ve Antakya Kalesi, Saint Pierre Kilisesi ve Harabeleri, Harbiye Şelaleleri ve Yenişehir Gölü çevresinden toplanan bitki örnekleri oluşturmaktadır. Araştırma alanlarına farklı vejetasyon dönemlerinde gidilmiş, toplanan bitki örnekleri herbaryum materyali olarak korunmaya uygun olacak biçimde preslenmiş ve tekniğine uygun olarak kurutulmuştur. Etiket üstü bilgisi için gerekli notlar (adres, lokalite, bitki no, habitat vs.) alınmıştır. Toplanan bitki örneklerinin teşhisi Adıyaman Üniversitesi
Herbaryumunda "Flora of Turkey and the East Aegean Islands" adlı eserden faydalanılarak yapılmıştır (Davis 1965-1985, Davisve ark. 1988, Güner ve ark. 2000). Bitki örnekleri Hatay Mustafa Kemal Üniversitesi Herbaryumu'nda (MKÜH) muhafaza edilmektedir. Bitki örneklerinin mevcut IUCN tehlike kategorileri (Güner ve ark. 2012, Vural 2006) ve Türkçe isimleri belirtilmiştir (Güner ve ark. 2012). Bitki örneklerinin latince isim kontrolleri yapılmıştır (Tübives 2020, Güner ve ark. 2012).

\section{Araştırma alanı tanıtımı}

Hatay ilinde bulunan 6 araştırma alanı "Flora of Turkey and the East Aegean Islands" adlı eserde kullanılan grid sistemine göre "C6" karesi içerisinde bulunur (Davis 19651985). Erzin Doğal Sit Alanı, Hatay ilinin Erzin İlçesi Başlamış Köyünde, merkezi noktası $36^{\circ} 56^{\prime} 33.32^{\prime \prime} \mathrm{K}-36^{\circ}$ $15^{\prime} 21$. 94" D koordinatlarında ve 334 metre rakımda bulunmaktadır. Gölbaşı Gölü, Hatay ilinin Kırıkhan İlçesi Gölbaşı Köyünde, merkezi noktası $36^{\circ} 30^{\prime} 11.40^{\prime \prime} \mathrm{K}-36^{\circ}$ 29' 38. 39" D koordinatlarında ve 92 metre rakımda bulunmaktadır. Habib-i Neccar Dağı ve Antakya Kalesi, Hatay ilinin Merkez İlçesi Narlıca Belediyesinde, merkezi bölgesi $36^{\circ} 11^{\prime}$ 53. $29^{\prime \prime} \quad \mathrm{K}-36^{\circ} 10^{\prime} \quad 37$. 90" D koordinatlarında ve 465 metre rakımda bulunmaktadır. Saint Pierre Kilisesi ve Harabeleri Hatay ilinin Merkez İlçesi Narlıca Belediyesinde, merkezi noktası $36^{\circ} 12^{\prime} 33.60^{\prime \prime} \mathrm{K}$ $36^{\circ} 10^{\prime} 41$. 94" D koordinatlarında ve 151 metre rakımda bulunmaktadır. Harbiye Şelaleleri Hatay ilinin Merkez İlçesi Harbiye Belediyesinde, merkezi noktası $36^{\circ} 08^{\prime} 17$. $35^{\prime \prime} \mathrm{K}-36^{\circ} 08^{\prime} 36.13^{\prime \prime} \mathrm{D}$ koordinatlarında ve 238 metre rakımda bulunmaktadır. Yenişehir Gölü Hatay ilinin Reyhanlı ilç̧esi Yenişehir Mahallesinde, merkezi noktası $36^{\circ} 14^{\prime}$ '17. $32^{\prime \prime} \mathrm{K}-36^{\circ} 34^{\prime} 03$. 12" D koordinatlarında ve 188 metre rakımda bulunmaktadır. Çalışma alanlarının gösterildiği coğrafik harita Google Maps (2020)'den faydalanılarak hazırlanmıştır (Şekil 1). 


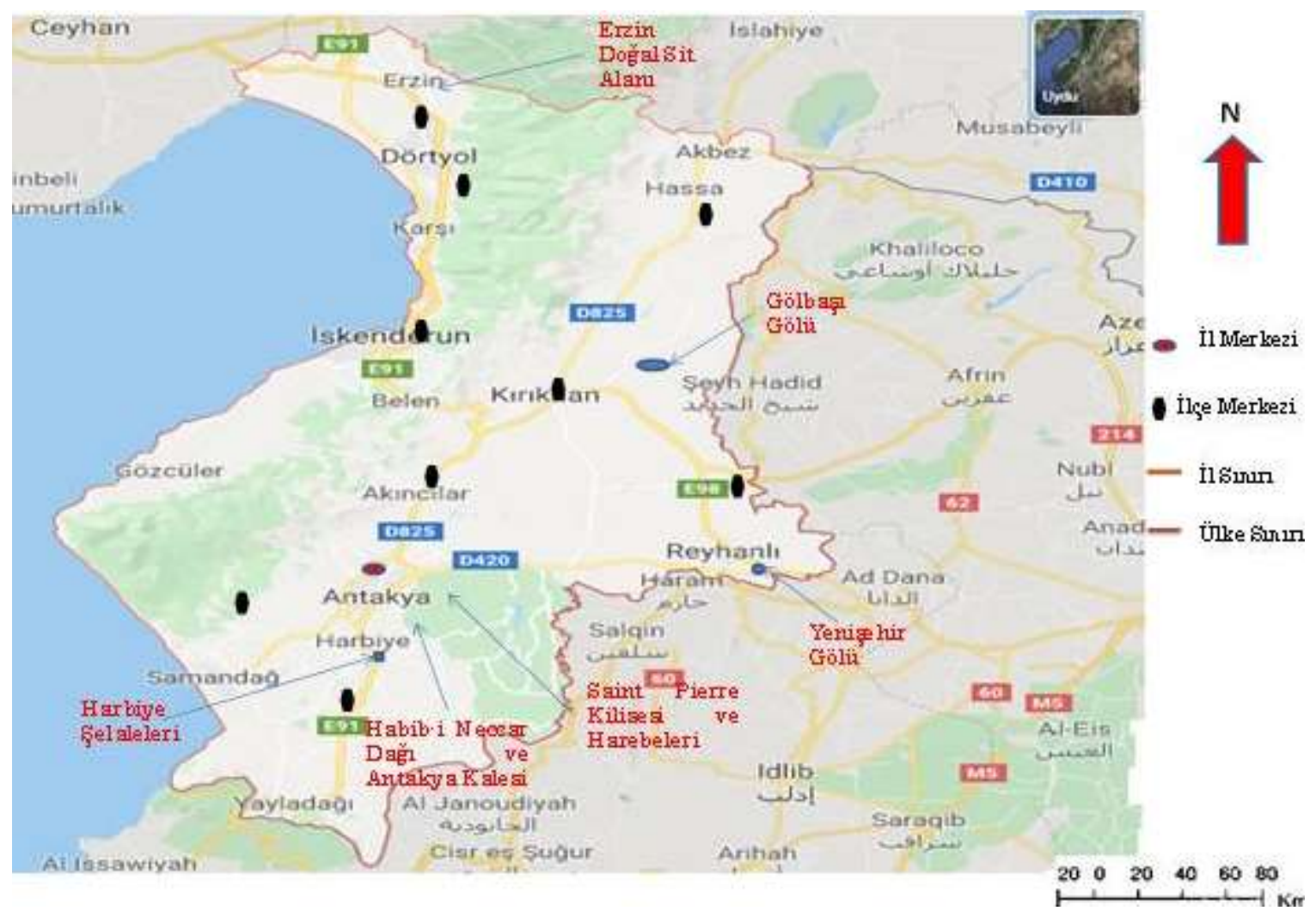

Şekil 1. Çalışma alanlarının konumu (Google Maps 2020).

Çalışma alanlarında kaya vejetasyonu, sucul alan vejetasyonu, daimî yeşil orman ve maki vejetasyonları mevcuttur (Ortaç 2017).

Hatay ilinin yıllık sıcaklık ortalaması $18.300^{\circ}$ 'dir. Ortalama sıcaklıklar yönünden en soğuk ay $8.0^{\circ} \mathrm{C}$ ile ocak, $27.8^{\circ} \mathrm{C}$ ile Ağustos ise en sıcak aydır. Çalışma alanında yıllık ortalama yağış miktarı 1168.2 mm'dir. En az yağışın görüldügü ay $16.0 \mathrm{~mm}$ ile haziran ayı, en çok yağışın görüldüğü ay ise $197.4 \mathrm{~mm}$ ile ocak ayıdır. Yıllık toplam yağışın mevsimsel olarak \%18.9'unun sonbahar, \%47.4'ünün kışın, \%28.1'inin ilkbahar ve \%5.6'sının da yazın düştüğü görülmüştür (Meteoroloji Genel Müdürlüğü 2020). Çalışma alanının iklim diyagramı Meteoroloji Genel Müdürlüğü (2020)'nün 1981-2010 yılları arasındaki elde edilen verilerine göre belirlenmiştir (Şekil 2). Haziran ayı ortasından başlayan ve ağustos ayı başına kadar süren kurak devre bulunmaktadır.

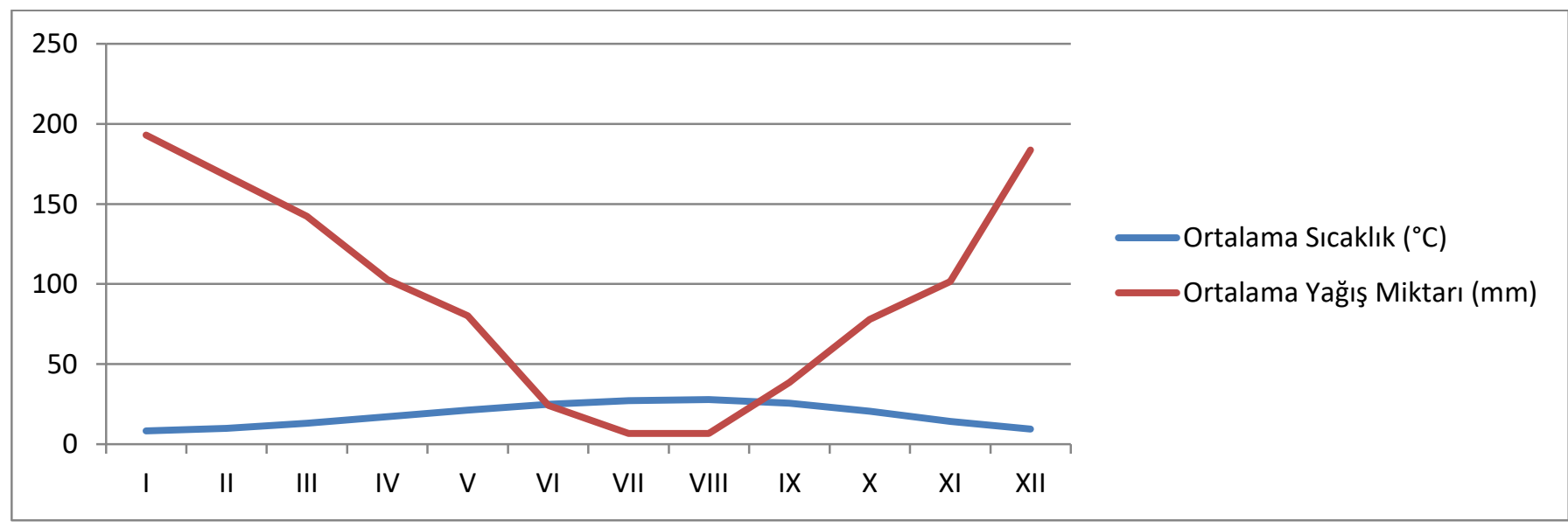

Şekil 2. Hatay ilinin iklim diyagramı (Meteoroloji Genel Müdürlüğü 2020). 
Çalışma alanında belirlenen bitkilerin teşhisi sonucunda, çalışma alanlarında 52 familyaya ait, 129 cins, 108 tür, 25 alttür ve 22 varyete olmak üzere, toplam 155 takson belirlenmiştir. Belirlenen bu taksonlardan 7 tanesi endemik olup, endemizm oranı $\% 4.5^{\prime}$ tir. Bu taksonlar bitki listesinin verildiği Çizelge de iki yıldız $\left(^{* *}\right)$ işareti ile gösterilmiştir.

Çalışma alanının florasını oluşturan taksonlar ile Tübives verilerinde bulunan taksonlardan aynı olanların sayısı 73 adet olup, bu taksonlar bitki listesinin verildiği Çizelge de tek yıldız $\left(^{*}\right)$ işareti ile gösterilmiştir. Çalışma alanının florasını oluşturan taksonların sahip oldukları familyalar, alfabetik sıraya göre listelenmiştir. Belirlenen taksonlar florastik listede sırasıyla; familya ismi, bilimsel ad, fitocoğrafik bölge, endemizm durumu/IUCN tehlike kategorisi ve Türkçe adı biçiminde belirtilmiştir. Belirlenen taksonların yer aldığı (bulunduğu) adresler numaralarla belirtilmiştir. Buna göre: 1: Erzin Doğal Sit Alanı, 2: Gölbaşı Gölü, 3: Habib-i Neccar Dağı ve Antakya
Kalesi, 4: Saint Pierre Kilisesi ve Harabeleri, 5: Harbiye Şelaleleri, 6: Yenişehir Gölü'dür (Çizelge 2).

\section{BULGULAR}

Araştırma sonucunda 52 familyaya ait, 129 cins, 108 tür, 25 alttür ve 22 varyete olmak üzere, toplam 155 takson belirlenmiştir. Belirlenen bu taksonlardan 7 tanesi endemik olup, endemizm oranı \%4.5'tir.

Çalışma alanında, tespit edilen taksonların fitocoğrafik bölgelere dağılımı şöyledir; Akdeniz (Doğu Akdeniz dahil) 57 takson (\%36.8), İran-Turan 7 takson (\%4.5), AvrupaSibirya 6 takson (\%3.9), Geniş yayılışlı 37 takson (\%23.9) ve bilinmeyen 48 (\%30.9) taksondur.Çalışma alanında tespit edilen taksonların fitocoğrafik bölgelere dağılımına bakıldığında Akdeniz elementinin (Doğu Akdeniz dâhil) 57 taksonla (\%36.8) birinci sırada bulunması çalışma alanlarının Akdeniz bölgesinde yer almasının doğal bir göstergesidir (Çizelge 1) .

Çizelge 1. Çalışma alanında belirlenen taksonların fitocoğrafik bölgelere göre dağılımları

\begin{tabular}{lcc}
\hline \multicolumn{1}{c}{ Fitocoğrafik Elementi } & Takson Sayısı & Oranı \\
\hline Akdeniz & 57 & $\% 36.8$ \\
İran-Turan & 7 & $\% 4.5$ \\
Avrupa-Sibirya & 6 & $\% 3.9$ \\
Geniş Yayılışlı & 37 & $\% 23.9$ \\
Bilinmeyenler & 48 & $\% 30.9$ \\
Toplam & 155 & $\% 100$ \\
\hline
\end{tabular}

Çalışma alanında 7 adet endemik ve 4 adet endemik olamayan (nadir) takson belirlenmiştir. Bu taksonlardan endemik olan 7'si ve endemik olmayan (nadir) 4'ü Akdeniz elementi (Doğu Akdeniz dahil)'dir. Belirlenen endemik taksonların ve endemik olmayan (nadir) taksonların IUCN tehlike kategorileri; 3 takson LC (en az endişe verici), 2 takson NT (tehdit altına girebilir), 1 takson CR (kritik) ve 5 takson VU (zarar görebilir) şeklindedir (Güner ve ark. 2012, vural 2006).

Çizelge 2. Çalışma alanında belirlenen bitki listesi

\begin{tabular}{|c|c|c|c|c|c|}
\hline Familya & Bilimsel Ad & $\begin{array}{l}\text { Fitocoğrafik } \\
\text { Bölge }\end{array}$ & $\begin{array}{l}\text { Ende- } \\
\text { mizm/ } \\
\text { IUCN }\end{array}$ & Türkçe Ad & Adres \\
\hline \multirow{3}{*}{ Anacardiaceae } & *PistaciapalaestinaBoiss. & Doğu Akdeniz & $-/$ & Menengiç & $1,2,5$ \\
\hline & Cotinus coggyria Scop. & - & $-/$ & Boyacı somağı & 5 \\
\hline & Rhus coriaria $\mathrm{L}$. & - & $-/$ & Sumak & 5 \\
\hline \multirow{2}{*}{ Apiaceae } & *Turgenia latifolia (L.) Hoffm & Geniş Yayılışlı & -1 & Karaheci & 2 \\
\hline & *Eryngium falcatum Delar. & Doğu Akdeniz & $-/$ & Çatal boğadikeni & 3 \\
\hline Apocynaceae & *Nerium oleander L. & Akdeniz & -1 & Zakkum & 2,5 \\
\hline Araliaceae & *Hedera helix L. & - & - / & Duvar Sarmaşığı & $2,3,4$ \\
\hline Asclepiadaceae & Cionura erecta (L.) Griseb. & Doğu Akdeniz & -1 & Babrik & 2 \\
\hline
\end{tabular}


Çizelge 2 (Devamı). Çalışma alanında belirlenen bitki listesi

\begin{tabular}{|c|c|c|c|c|c|}
\hline Familya & Bilimsel Ad & $\begin{array}{l}\text { Fitocoğrafik } \\
\text { Bölge }\end{array}$ & $\begin{array}{l}\text { Ende- } \\
\text { mizm/ } \\
\text { IUCN }\end{array}$ & Türkçe Ad & Adres \\
\hline \multirow{13}{*}{ Asteraceae } & Calendula arvensis $\mathrm{L}$. & Geniş Yayılışlı & $-/$ & Portakal nergisi & 2 \\
\hline & *Centaurea ptosimopappa Hayek & Doğu Akdeniz & $* * / \mathrm{VU}$ & Meşe sarıbaşı & 1 \\
\hline & ${ }^{*}$ Crepis sancta (L.) Babcock & Geniş Yayılışlı & $-/$ & Yaban kıskısı & 1,2 \\
\hline & *Inula graveolens(L.) Desf. & Akdeniz & $-/$ & Deli sarıot & 2 \\
\hline & *I. viscosa (L.) Aiton & Akdeniz & $-/$ & Sümenit & $1,2,5$ \\
\hline & $\begin{array}{l}\text { Matricaria chamomilla L. var. recutita } \\
\text { (L.)Grierson }\end{array}$ & Geniş Yayılışlı & -1 & Alman papatyası & 2 \\
\hline & ${ }^{*}$ Notobasis syriaca (L.) Cass & Akdeniz & $-/$ & Yavan kenger & 2 \\
\hline & Picnomon acarna (L.) Cass. & Akdeniz & $-/$ & Kılçık diken & 2 \\
\hline & ${ }^{*}$ Senecio vernalis Waldst \& Kit & Geniş Yayılışlı & $-/$ & Kanarya otu & $1,2,3,4$ \\
\hline & *Silybum marianum (L.) Gaertner & Akdeniz & $-/$ & Devedikeni & 2 \\
\hline & Sonchus oleraceus L. & - & $-/$ & Zoko & 2 \\
\hline & Xanthium spinosum L. & - & $-/$ & Pitrak & 5 \\
\hline & Xeranthemum annuum L. & Geniş Yayılışlı & -1 & Kâğıt çiçeği & 2 \\
\hline \multirow{3}{*}{ Boraginaceae } & Anchusa azurea Miller var. azurea & Geniş Yayılışlı & $-/$ & Sığırdili & 2 \\
\hline & *Heliotropium europaeum L. & Akdeniz & $-/$ & Akrep otu & 2 \\
\hline & *Onosma rascheyanum Boiss. & İran-Turan & -1 & Emzik otu & 4 \\
\hline \multirow{5}{*}{ Brassicaceae } & $\begin{array}{l}\text { *Alyssum samariferum Boiss \& } \\
\text { Hausskn }\end{array}$ & - & -1 & Kanatlı kevke & 1 \\
\hline & *Capsella bursa-pastoris (L.) Medik. & Geniş Yayılışlı & $-/$ & Çobançantasi & 1 \\
\hline & Lepidium perfoliatum L. & Geniş Yayılışlı & $-/$ & Gübre otu & 2 \\
\hline & Nasturtium officinale R. Br. & Geniş yayılışlı & $-/$ & Su teresi & 2,5 \\
\hline & *Sinapis arvensis L. & Geniş Yayılışlı & $-/$ & Hardal & 2 \\
\hline Campanulaceae & $\begin{array}{l}\text { *Michauxia campanuloides L'Herit ex } \\
\text { Aiton }\end{array}$ & Doğu Akdeniz & -1 & Keşir & 1 \\
\hline Capparaceae & Capparis spinosa L. var. spinosa & - & -1 & $\begin{array}{l}\text { Kapari (Kebere, } \\
\text { Keditırnağı) }\end{array}$ & 2,5 \\
\hline \multirow{5}{*}{ Caryophyllaceae } & *Dianthus polycladus Boiss. & Doğu Akdeniz & $-/ V U$ & Belen karanfili & 2 \\
\hline & $\begin{array}{l}\text { Holosteum umbellatum L. var. } \\
\text { umbellatum }\end{array}$ & - & -1 & Şeytan küpesi & 2 \\
\hline & $\begin{array}{l}\text { *Silene aegyptiaca (L.) L. fil. subsp. } \\
\text { aegyptiaca }\end{array}$ & - & $-/$ & Ballıca & 1 \\
\hline & S. colorata Poiret & - & -1 & Kum nakılı & 2 \\
\hline & S. viscosa (L) Pers & - & -1 & Konya gıvışkanı & 4 \\
\hline \multirow{2}{*}{ Cistaceae } & Cistus creticus L. & Akdeniz & $-/$ & Laden & $1,3,4$ \\
\hline & ${ }^{*}$ C. salviifolius L & Geniş Yayılışlı & -1 & Kartli & 1 \\
\hline \multirow[t]{2}{*}{ Crassulaceae } & Sedum album L. & Geniş Yayılışlı & -1 & Çoban kavurgası & $2,3,4$ \\
\hline & Cupressus sempervirens L. & - & -1 & Servi & 5 \\
\hline Cupressaceae & $\begin{array}{l}\text { Juniperus oxycedrus L. subsp. } \\
\text { oxycedrus }\end{array}$ & Geniş Yayılışlı & -1 & Katran ardıcı & 3,4 \\
\hline Cyperaceae & $\begin{array}{l}{ }^{*} \text { Bolboschoenus maritimus } \\
\text { Pallavar. maritimus }\end{array}$ & Geniş Yayılışlı & -1 & Sandalyesazı & 2 \\
\hline Ephedraceae & Ephedra foeminea Forssk. & - & -1 & Denizüzümü & 2 \\
\hline Equisetaceae & Equisetum hyemale L. & - & -1 & Ulamotu & 5 \\
\hline \multirow{2}{*}{ Ericaceae } & Arbutus unedo L. & - & -1 & Kocayemiş & 1,5 \\
\hline & *Erica manipuliflora Salisb. & Doğu Akdeniz & -1 & Püren & 1 \\
\hline \multirow{2}{*}{ Euphorbiaceae } & *Euphorbia aleppica L. & Geniş Yayılışlı & -1 & Haşul & 4 \\
\hline & Ricinus communis L. & Geniş Yayılışı & -1 & Hint yağı & 5 \\
\hline
\end{tabular}


Çizelge 2 (Devamı). Çalışma alanında belirlenen bitki listesi

\begin{tabular}{|c|c|c|c|c|c|}
\hline Familya & Bilimsel Ad & $\begin{array}{l}\text { Fitocoğrafik } \\
\text { Bölge }\end{array}$ & $\begin{array}{l}\text { Ende- } \\
\text { mizm/ } \\
\text { IUCN }\end{array}$ & Türkçe Ad & Adres \\
\hline \multirow{22}{*}{ Fabaceae } & $\begin{array}{l}\text { Alhagi maurorum subsp. maurorum } \\
\text { Medik. }\end{array}$ & İran-Turan & $-/$ & Agul dikeni & 2 \\
\hline & Astragalus hamosus L. & - & -1 & Koç boynuzu & 2 \\
\hline & ${ }^{*} A$. schizopterus Boiss. & Doğu Akdeniz & $-/$ & Kedi çomağı & 3 \\
\hline & Calicotome villosa (Poiret) Link & Akdeniz & $-/$ & Keçi boğan & $1,3,4,5$ \\
\hline & Ceratonia siliqua L. & Akdeniz & $-/$ & Keçiboynuzu & 5 \\
\hline & $\begin{array}{l}\text { Cercis sliquastrum L. subsp. } \\
\text { hebecarpa (Bornm.) Yalt. }\end{array}$ & - & $-/$ & Zazalak & 1 \\
\hline & *Cytisus drepanolobusBoiss. & Doğu Akdeniz & $* * / \mathrm{NT}$ & Has kuşçubuğu & 1 \\
\hline & $\begin{array}{l}\text { *Hippocrepis emerussubsp. } \\
\text { emeroides (Boiss. \& Spruner) Lassen }\end{array}$ & - & $-/$ & Telgevrecik & $1,3,4$ \\
\hline & $\begin{array}{l}\text { Genista januensissubsp. lydia (Boiss.) } \\
\text { Kit Tan \& Ziel. }\end{array}$ & Doğu Akdeniz & $-/ \mathrm{VU}$ & Geyikborcağı & 1 \\
\hline & $\begin{array}{l}\text { *Glycyrrhiza glabra L. var. } \\
\text { glandulifera (Waldst. \& Kit.) Boiss. }\end{array}$ & Geniş Yayılışlı & $-/$ & Meyan & 5 \\
\hline & Hymenocarpus circinnatus (L.) Savi & Akdeniz & -1 & Pullu ot & 2 \\
\hline & Lathyrus variabilis(Boiss. \&Ky.) Maly & Doğu Akdeniz & $-/ V U$ & Bayır burçağı & 1 \\
\hline & Medicago radiata $\mathrm{L}$. & İran-Turan & $-/$ & Hilal yonca & 2 \\
\hline & $\begin{array}{l}\text { *Ononis viscosa L. subsp. breviflora } \\
\text { (DC.) Nyman, }\end{array}$ & - & -1 & Siyek dikeni & 2 \\
\hline & $\begin{array}{l}\text { *Pisum sativum L. subsp. elatius } \\
\text { (Bieb.) Aschers. \& Graebn var. elatius }\end{array}$ & Akdeniz & $-/$ & Boylu bezelye & 3 \\
\hline & $\begin{array}{l}\text { *Prosopis farcta (Banks \& Sol.) } \\
\text { Macbride }\end{array}$ & - & $-/$ & Çedi otu & 2,5 \\
\hline & Trifolium repens L.var. repens & - & -1 & Ak üçgül & 2 \\
\hline & ${ }^{*} T$. stellatum L. var. stellatum & - & $-/$ & Yonca & 2 \\
\hline & Vicia cracca L. subsp. cracca & Avrupa-Sibirya & $-/$ & Kuş fiği & 2 \\
\hline & V. faba L. & - & -1 & Bakla & 2 \\
\hline & *V. hybrida L. & Geniş Yayılışlı & -1 & Melez bakla & 1 \\
\hline & *V. villosa Roth subsp. villosa & Geniş Yayılışlı & -1 & Tüylüfiğ & 1 \\
\hline \multirow{3}{*}{ Fagaceae } & *Quercus cerris L. var. cerris & Akdeniz & -1 & Saçlı meşe & 1 \\
\hline & Q. coccifera $\mathrm{L}$. & Akdeniz & -1 & Kermes Meşesi & $1,3,4$ \\
\hline & $\begin{array}{l}{ }^{*} Q . \text { infectoriasubsp. veneris(A. Kern.) } \\
\text { Meikle }\end{array}$ & - & -1 & Zindiyen & 1 \\
\hline \multirow{3}{*}{ Geraniaceae } & *Erodium cicutarium & - & -1 & İğnelik & 2 \\
\hline & $\begin{array}{l}\text { L'Heritsubsp. cicutarium } \\
{ }^{*} \text { E. malacoides (L) L'Herit }\end{array}$ & Akdeniz & -1 & Dönbaba & 2 \\
\hline & Geranium molle L. subsp. molle & - & -1 & Yumuşakıtır & 2,4 \\
\hline Hypericaceae & $\begin{array}{l}\text { *Hypericum thymifolium Banks and } \\
\text { Sol }\end{array}$ & Doğu Akdeniz & -1 & Çam kantaronu & 3,4 \\
\hline Iridaceae & Iris unguicularis Poiret & Akdeniz & -1 & Çalı navruzu & 1,3 \\
\hline \multirow{4}{*}{ Lamiaceae } & $\begin{array}{l}\text { *Ajuga chamaepitys (L.) } \\
\text { Schrebersubsp. chia (Schreber) } \\
\text { Arcangelivar. chia }\end{array}$ & Geniş Yayılışlı & $-/$ & AcıgıCI & 2 \\
\hline & A. orientalis L. & - & -1 & Dağ mayasılı & 4 \\
\hline & $\begin{array}{l}\text { *Ballota saxatilis Sieber ex J. \& C. } \\
\text { Presl subsp. saxatilis }\end{array}$ & Doğu Akdeniz & -1 & Nemnemotu & 2 \\
\hline & $\begin{array}{l}\text { Lamium purpureum L. var. } \\
\text { purpureum }\end{array}$ & Avrupa-Sibirya & -1 & Ballıbaba & 1 \\
\hline
\end{tabular}


Çizelge 2 (Devamı). Çalışma alanında belirlenen bitki listesi

Familya

Bilimsel Ad

Fitocoğrafik

Bölge

Ende-

mizm/

Türkçe Ad

Adres

IUCN

\begin{tabular}{|c|c|c|c|c|c|}
\hline \multirow{12}{*}{ Lamiaceae } & $\begin{array}{l}\text { Mentha longifolia (L.) Hudson, subsp. } \\
\text { typhoides (Briq.) Harley }\end{array}$ & Geniş Yayılışlı & $-/$ & Dere nanesi & 2 \\
\hline & $\begin{array}{l}\text { *Origanum syriacum L. subsp. bevanii } \\
\text { (Holmes) Greuter \& Burdet }\end{array}$ & Doğu Akdeniz & $-/$ & Tarsus kekiği & 3,4 \\
\hline & *Salvia aramiensis Rech. fil. & Doğu Akdeniz & $-/ V U$ & Pohur & 1 \\
\hline & ${ }^{*} S$. tomentosa Miller & Akdeniz & -1 & Şalba & 1 \\
\hline & S. viridis L. & Akdeniz & $-/$ & Zarif şalba & 2 \\
\hline & Scutellaria brevibracteata subsp. & & & & 2 \\
\hline & $\begin{array}{l}\text { subvelutina (Rech. f.) Greuter \& } \\
\text { Burdet }\end{array}$ & Doğu Akdeniz & $-/$ & Karide & \\
\hline & $\begin{array}{l}\text { Stachys annua (L.) L. subsp. } \\
\text { ammophila (Boiss, \& B1.) Samuelss }\end{array}$ & Doğu Akdeniz & -1 & Kumçayçesi & 4 \\
\hline & $\begin{array}{l}{ }^{*} \text { S. cretica L. subsp. mersinaea } \\
\text { (Boiss.) Rech. fil. }\end{array}$ & Doğu Akdeniz & $* * / L C$ & Boncuk şalba & 2 \\
\hline & *S. pumila Banks \& Sol. & Doğu Akdeniz & $* * / \mathrm{NT}$ & Sarı karabaş & 3,4 \\
\hline & $\begin{array}{l}\text { Teucrium chamaedrys L. subsp. } \\
\text { tauricolum Rech. fil. }\end{array}$ & Doğu Akdeniz & $* * /$ LC & Kısamahmuotu & 2 \\
\hline & T. polium L. & Geniş Yayılışıı & -1 & Acı yavşan & 2 \\
\hline \multirow{9}{*}{ Liliaceae } & Asparagus acutifolius L. & Akdeniz & -1 & Tilkişen & 1 \\
\hline & ${ }^{*}$ Asphodelus aestivus Brot & Akdeniz & $-/$ & Kirgiç kökü & $2,3,4$ \\
\hline & $\begin{array}{l}\text { *Hyacinthus orientalis L. subsp. } \\
\text { orientalis }\end{array}$ & Doğu Akdeniz & -1 & Sümbül & 3 \\
\hline & Muscari babachii Eker\& Koyuncu & Akdeniz & $* * / \mathrm{CR}$ & Tekin Sümbülü & 1,3 \\
\hline & ${ }^{*} M$. inconstrictum Rech. fil. & İran-Turan & -1 & İnce müşkürüm & 2 \\
\hline & M. parviflorum Desf. & Akdeniz & - / & Güz müşkürümü & 2 \\
\hline & Ruscus aculeatus L. & - & -1 & Tavşanmemesi & 1 \\
\hline & *Smilax aspera L. & - & -1 & Gıcırdikeni & 1 \\
\hline & *Urginea maritima (L.) Baker & Akdeniz & -1 & Ada soğanı & 4 \\
\hline Malvaceae & *Malva sylvestris $\mathrm{L}$. & - & -1 & Ebegümeci & 2 \\
\hline \multirow{3}{*}{ Moraceae } & Ficus carica L. subsp. carica & Geniş Yayılışlı, & -1 & İncir & 6 \\
\hline & $\begin{array}{l}\text { F. carica L. subsp. rupestris (Hausskn.) } \\
\text { Browicz }\end{array}$ & İran-Turan & $-/$ & İt inciri & 2,5 \\
\hline & Morus alba L. & Geniş Yayılışlı & -1 & Ak dut & 6 \\
\hline \multirow{3}{*}{ Myrtaceae } & *Eucalyptus camaldulensis Dehnh. & - & -1 & Sıtma ağacı & 5,6 \\
\hline & $\begin{array}{l}\text { *Myrtus communis L. } \quad \text { subsp. } \\
\text { communis }\end{array}$ & - & $-/$ & Mersin & $1,3,4$ \\
\hline & Punica granatum L. & - & -1 & Nar & 6 \\
\hline Nymphaeaceae & ${ }^{*}$ Nuphar lutea (L.) Sm & - & -1 & Sarı nilüfer & 2 \\
\hline \multirow{3}{*}{ Oleaceae } & Jasminum fruticans L. & Akdeniz & -1 & Boruk & $2,3,4$ \\
\hline & *Olea europaea L. var. europaea & - & $-/$ & Zeytin & 3,4 \\
\hline & Phillyrea latifolia L. & Akdeniz & -1 & Akçakesme & 1 \\
\hline Onagraceae & *Epilobium angustifolium L. & Geniş Yayılışlı & -1 & Yakı otu & 2 \\
\hline \multirow{4}{*}{ Orchidaceae } & *Epipactis helleborine (L.) Crantz & Geniş Yayılışlı & -1 & Bindallı çiçeği & 1 \\
\hline & *Ophrys vernixia Brot. subsp. vernixia & Akdeniz & -1 & Arı salebi & 3 \\
\hline & Orchis anatolica Boiss. & Doğu Akdeniz & $-/$ & Dildamak & 3 \\
\hline & O. simia Lam. & Akdeniz & -1 & Salep püskülü & 3 \\
\hline \multirow{3}{*}{ Papaveraceae } & Fumaria asepala Boiss. & İran-Turan & -1 & Ak şahtere & 2,3 \\
\hline & Papaver rhoeas L. & Geniş Yayılışlı & - / & Gelincik & 2,4 \\
\hline & ${ }^{*} P$. syriacum Boiss \& Blanche & - & -1 & Kellinar & 2 \\
\hline Pinaceae & Pinus brutia Ten. & Doğu Akdeniz & -1 & Kızılçam & $1,3,5,6$ \\
\hline
\end{tabular}


Çizelge 2 (Devamı). Çalışma alanında belirlenen bitki listesi

\begin{tabular}{|c|c|c|c|c|c|}
\hline Familya & Bilimsel Ad & $\begin{array}{l}\text { Fitocoğrafik } \\
\text { Bölge }\end{array}$ & $\begin{array}{l}\text { Ende- } \\
\text { mizm/ } \\
\text { IUCN }\end{array}$ & Türkçe Ad & Adres \\
\hline \multirow{2}{*}{ Plantaginaceae } & *Plantago lanceolata $\mathrm{L}$ & Geniş Yayılışlı & -1 & Damarlıca & 2 \\
\hline & P. major L. subsp. major & - & -1 & Sinirotu & 5 \\
\hline Platanaceae & Platanus orientalis L. & Geniş Yayılışlı & $-/$ & Çınar & 5,6 \\
\hline \multirow{3}{*}{ Poaceae } & Arundo donax $\mathrm{L}$. & - & $-/$ & Kargı & 5 \\
\hline & $\begin{array}{l}\text { Phragmites australis (Cav.) Trin. ex } \\
\text { Steudel }\end{array}$ & Avrupa-Sibirya & -1 & Kamış & 2,5 \\
\hline & *Themeda triandra Forsskal & Geniş Yayılışlı & -1 & Kızılot & 1 \\
\hline Potamogetonaceae & Potamogeton nodosus Poiret & - & -1 & Düğmeli Su otu & 2 \\
\hline \multirow{3}{*}{ Primulaceae } & ${ }^{*}$ Anagallis arvensis L. var. arvensis & - & -1 & Farekulağı & 2 \\
\hline & ${ }^{*}$ Cyclamen coum Miller var. coum & - & $-/$ & Yersomunu & 1 \\
\hline & ${ }^{*}$ C. persicum Miller & Doğu Akdeniz & -1 & Ala Yaprak & 4 \\
\hline \multirow{5}{*}{ Ranunculaceae } & Adonis aestivalis L. subsp. aestivalis & Geniş Yayılışlı & -1 & Kan damlası & 2 \\
\hline & *Anemone coronaria $\mathrm{L}$. & Akdeniz & -1 & Manisa lalesi & 3 \\
\hline & Nigella unguicularis (Lam.) Spenner & - & -1 & Şehniz & 2 \\
\hline & Ranunculus arvensis $\mathrm{L}$. & Geniş Yayılışlı & $-/$ & Mustafa çiçeği & 2 \\
\hline & ${ }^{*} R$. asiaticus L. & - & -1 & Şakayık lalesi & 2 \\
\hline \multirow[t]{2}{*}{ Rhamnaceae } & $\begin{array}{l}\text { Rhamnus oleoides L. subsp. graecus } \\
\text { (Boiss.\& Reut.) Holmboe }\end{array}$ & Doğu Akdeniz & -1 & Cehri & 3,5 \\
\hline & Zizyphus lotusWilld. & - & -1 & Sarı hünnap & 2 \\
\hline \multirow{5}{*}{ Rosaceae } & $\begin{array}{l}\text { Crataegus monogyna Jacg subsp. } \\
\text { monogyna }\end{array}$ & Geniş Yayılışlı & -1 & Yemişen & 1 \\
\hline & Potentilla calycina Boiss. and Bal. & Doğu Akdeniz & $* * / \mathrm{LC}$ & İçel parmakotu & 1 \\
\hline & *Rubus sanctus Schreber & Geniş Yayılışlı & -1 & Böğürtlen & $3,5,6$ \\
\hline & Sarcopoterium spinosum (L.) Spach & Doğu Akdeniz & -1 & Abdestbozanotu & $2,3,4,5$ \\
\hline & $\begin{array}{l}\text { Sorbus umbellata (Desf.) Fritsch var. } \\
\text { umbellata }\end{array}$ & - & -1 & Dağın & 5 \\
\hline \multirow[b]{2}{*}{ Salicaceae } & *Populus alba L. & Avrupa-Sibirya & -1 & Ak kavak & \multirow{2}{*}{$\begin{array}{c}5,6 \\
1\end{array}$} \\
\hline & Salix acmophylla Boiss. & İran-Turan & -1 & Acem söğüdü & \\
\hline Scrophulariaceae & Verbascum sinuatum L. var. sinuatum & Akdeniz & -1 & Bodanotu & 2 \\
\hline Simaroubaceae & Ailanthus altissima (Miller) Swingle & - & -1 & Kokarağaç & 5,6 \\
\hline Solanaceae & Solanum nigrum L. subsp. nigrum & - & -1 & İt üzümü & 5 \\
\hline Thymelaeaceae & *Daphne sericea Vahl & Doğu Akdeniz & -1 & Tavukbüzüğü & 1,5 \\
\hline Ulmaceae & *Ulmus glabra Hudson & Avrupa-Sibirya & -1 & Dağ karağacı & 6 \\
\hline \multirow{2}{*}{ Urticaceae } & Parietaria judaica L. & Geniş Yayılışlı & -1 & Duvarfesleğeni & 3,4 \\
\hline & Urtica dioica $\mathrm{L}$. & Avrupa-Sibirya & -1 & Isırgan & 2 \\
\hline Vebenaceae & *Verbena officinalis L. & Geniş Yayılışlı & -1 & Mine çiçeği & 2 \\
\hline Vitaceae & $\begin{array}{l}\text { *Ampelopsis orientale } \\
\text { Planchon }\end{array}$ & - & -1 & Bikir asması & 5 \\
\hline
\end{tabular}

\section{TARTIŞMA ve SONUÇ}

Çalışma alanı ve yakın bölgelerinde yapılan çalışmaların endemizm oranlarına bakıldığında en yüksek endemizm oranının \%9.3 ile Musa Dağı, en düşük endemizm oranının ise \%5.6 ile Kuseyr (Habib-in Neccar) Dağları'nda yapılan flora çalışmalarıdır (Düzenli ve Çakan 2001, Yolcu 1998).
Musa Dağı'ında yapılan florastik çalışmada endemizm oranının yüksek çıkması, bizim ve diğer alanlara göre farklı mikroklima özelliği, yükselti ve habitatlara sahip olması ile açıklanabilir. Çalışma alanlarımızın endemizm oranının \%4.5 ile düşük oranda çıkması ise stabil habitatların (sulak) varlığı ile açıklanabilir (Çizelge 3). Çalışma alanı ile yakın bölgelerinde yapılan çalışmalar, taksonların 
fitocoğrafik bölgelere dağılımına göre karşılaştıııldığında, çalışmaların hepsinde (Yolcu 1998, Türkmen ve Düzenli 1998, Düzenli ve Çakan 2001, Kayıkçı 2006) Akdeniz fitocoğrafik bölge elementinin yüksek olduğu görülmektedir. Bu durum çalışma alanlarının Akdeniz bölgesinde bulunmasına bağlanabilir (Çizelge 4)

Çizelge 3. Çalışma alanı ve yakın bölgelerinde yapılan çalışmaların endemizm oranları

\begin{tabular}{|c|c|c|}
\hline No & Araştırma Alanı & Endemizm Oranı \\
\hline 1 & Çalışma alanı & $\% 4.5$ \\
\hline 2 & Kuseyr (Habib-in Neccar) Dağları (Yolcu 1998) & $\% 5.6$ \\
\hline 3 & The Flora of Dörtyol and Erzin Districts (Türkmen ve Düzenli 1998) & $\% 7.5$ \\
\hline 4 & Musa Dağı (Düzenli ve Çakan 2001) & $\% 9.3$ \\
\hline 5 & Samandağ (Hatay) Kıyı Kumulları (Kayıkçı 2006) & - \\
\hline
\end{tabular}

Çizelge 4.Çalışma alanı ve yakın bölgelerinde yapılan çalışmalardaki taksonların fitocoğrafik bölgelere dağılım oranları

\begin{tabular}{clcccc}
\hline No & \multicolumn{1}{c}{ Araştırma Alanı } & $\begin{array}{c}\text { Akdeniz } \\
\text { elementi }\end{array}$ & $\begin{array}{c}\text { İran-Turan } \\
\text { elementi }\end{array}$ & $\begin{array}{c}\text { Avrupa-Sibirya } \\
\text { elementi }\end{array}$ & $\begin{array}{c}\text { Geniş Yayılışlı ve } \\
\text { bilinmeyenler }\end{array}$ \\
\hline 1 & Çalışma alanı & $\% 36.8$ & $\% 4.5$ & $\% 3.9$ & $\% 54.8$ \\
2 & Kuseyr (Habib-in Neccar) Dağları (Yolcu 1998) & $\% 38.2$ & $\% 5.6$ & $\% 2.4$ & $\% 53.8$ \\
3 & The Flora of Dörtyol and Erzin Districts (Türkmen & $\% 29.9$ & $\% 5.8$ & $\% 10.3$ & \\
& ve Düzenli 1998) & & & $\% 8.2$ & $\% 47.3$ \\
4 & Musa Dağı (Düzenli ve Çakan 2001) & $\% 40.8$ & $\% 3.6$ & $\% 2.5$ & $\% 64.1$ \\
5 & Samandağ (Hatay) Kıyı Kumulları (Kayıkçı 2006) & $\% 33.4$ & - & & $\%$ \\
\hline
\end{tabular}

Çalışma alanı ile yakın bölgelerinde yapılan çalışmalarda, en fazla takson içeren familyalar bakımından karşılaştırıldığında; bütün çalışmalarda Fabaceae familyasının araştırma alanımızda olduğu gibi ilk sırada bulunduğu görülmektedir (Yolcu 1998, Türkmen ve
Düzenli 1998, Düzenli ve Çakan 2001, Kayıkçı 2006)."Flora of Turkey and the East Aegean Islands" adlı eserde de (Davis 1965-1985) Asteraceae ve Fabaceae familyaları ilk iki sırada yer alırlar (Çizelge 5).

Çizelge 5. Çalışma alanı ve yakın bölgelerinde yapılan çalışmalardan en çok takson içeren familyalar

\begin{tabular}{|c|c|c|c|c|c|}
\hline No & Araştırma Alanı & Fabaceae & Lamiaceae & Asteraceae & Liliaceae \\
\hline 1 & Çalışma alanı & 22 & 15 & 13 & 9 \\
\hline 2 & $\begin{array}{l}\text { Kuseyr (Habib-in Neccar) Dağları (Yolcu } \\
\text { 1998) }\end{array}$ & 26 & 19 & 17 & 10 \\
\hline 3 & $\begin{array}{l}\text { The Flora of Dörtyol and Erzin Districts } \\
\text { (Türkmen ve Düzenli 1998) }\end{array}$ & 77 & 38 & 67 & 29 \\
\hline 4 & Musa Dağı (Düzenli ve Çakan 2001) & 67 & 45 & 55 & 16 \\
\hline 5 & $\begin{array}{l}\text { Samandağ (Hatay) Kıyı Kumulları (Kayıkçı } \\
\text { 2006) }\end{array}$ & 26 & 2 & 24 & 7 \\
\hline
\end{tabular}

Çalışma alanı ile yakın bölgelerinde yapılan çalışmalarda en fazla takson içeren cinsler bakımından karşılaştırıldığında; Çalışma alanımızda birinci sırada 4 taksonla Vicia cinsi bulunmaktadır. Vicia cinsi The Flora of Dörtyol and Erzin Districts (Türkmen ve Düzenli 1998), Musa Dağı (Düzenli ve Çakan 2001) ve Samandağ (Hatay)
Kıyı Kumulları (Kayıkçı 2006) çalışmalarında da birinci sırada yer almaktadır. Bu durum coğrafik yakınlıklar ile açıklanabilir. Kuseyr (Habib-in Neccar) Dağları (Yolcu 1998) adlı çalışmada farklı cinslerin ilk sırada yer alması habitat farklılı̆ıı ile açıklanabilir (Çizelge 6). 
Çizelge 6. Çalışma alanı ve yakın bölgelerinde yapılan çalışmalardaen çok takson içeren cinsler

\begin{tabular}{|c|c|c|c|c|c|c|c|}
\hline No & Araştırma Alanı & Vicia & Silene & Stachys & Quercus & Salvia & Muscari \\
\hline 1 & Çalışma alanı & 4 & 3 & 3 & 3 & 3 & 3 \\
\hline 2 & $\begin{array}{l}\text { Kuseyr (Habib-in Neccar) Dağları (Yolcu } \\
\text { 1998) }\end{array}$ & 2 & 1 & 3 & 2 & 3 & 2 \\
\hline 3 & $\begin{array}{l}\text { The Flora of Dörtyol and Erzin Districts } \\
\text { (Türkmen ve Düzenli 1998) }\end{array}$ & 8 & 7 & 3 & 5 & 3 & 3 \\
\hline 4 & Musa Dağı (Düzenli ve Çakan 2001) & 11 & 4 & 7 & 1 & 5 & 2 \\
\hline 5 & $\begin{array}{l}\text { Samandağ (Hatay) Kıyı Kumulları (Kayıkçı } \\
\text { 2006) }\end{array}$ & 3 & 2 & - & - & 1 & 2 \\
\hline
\end{tabular}

\section{TEŞEKKÜR}

$\mathrm{Bu}$ araştırmanın bir kısmı Adıyaman Üniversitesi Fen Bilimleri Enstitüsü Biyoloji Anabilim dalı Yüksek Lisans öğrencisi İshak ORTAÇ'ın tezinden (FEFYL-2016-0010 nolu BAP projesi) bir kısmı ise Çevre ve Şehircilik Bakanlığı'nın 2014/151078 numaralı projesinin sonuç raporundan üretilmiştir. Her iki kuruma maddi desteklerinden dolayı teşekkür ederiz.

\section{KAYNAKLAR}

Davis PH (1965-1985) Flora of Turkey and the East Aegean Islands, Vol.1-9. Edinburgh Univ. Press, Edinburgh.

Davis PH, Mill R, Tan K (1988) Flora of Turkey and the East Aegean Islands, Vol.10.Edinburgh Univ. Press, Edinburgh.

Düzenli A, Çakan H (2001) Flora of Mount Musa (Hatay- Turkey), Tubitak Tr. J. of Bot, 25:285-389.

Erik S, Tarıkahya B (2004) Türkiye Florası Üzerine. Kebikeç İnsan Kaynakları Araştırmaları Dergisi,17:139-163.

Google Maps (2020) Google Haritaları, https://www.google.com/maps/@39.0876459,35.1777724,6z.

Güner A, Özhatay N, Ekim T, Başer KHC (2000) Flora of Turkey andthe East Aegean Islands, Edinburgh Univ. Press Vol. 11, Edinburgh, $656 \mathrm{pp}$.
Güner A, Aslan S, Ekim T, Vural M, Babaç MT (2012) Türkiye Bitkileri Listesi (Damarlı Bitkiler), Nezahat Gökyiğit Botanik Bahçesi ve Flora Araştırmaları Derneği Yayını, İstanbul, $263 \mathrm{~s}$.

Kayıkçı S (2006) Samandağ (Hatay) Kıyı Kumullarının Florası. Hatay Mustafa Kemal Üniversitesi Fen Bilimleri Enstitüsü Biyoloji Anabilim Dalı, Yüksek Lisans Tezi, Hatay, $60 \mathrm{~s}$.

Meteoroloji Genel Müdürlüğü (2020) illere Ait Mevsim Normalleri (1981-2010), https://www.mgm.gov.tr/ veridegerlendirme / il-veilçeler istatistik.aspx?m=HATAY.

Ortaç I (2017) Doğu Akdeniz Bölgesinde Bulunan Bazı Doğal ve Kültürel SitAlanlarının Bitki Örtüsü Üzerine Araştırmalar. Adıyaman Üniversitesi Fen Bilimleri Enstitüsü Biyoloji Anabilim Dalı, Yüksek Lisans Tezi, Adıyaman, $96 \mathrm{~s}$.

T.C. Çevre ve Şehircilik Bakanlığı (2016) Adana, Hatay, Mersin, Kahramanmaraş, Osmaniye, Gaziantep ve Kilis illeri Doğal SitAlanlarının Ekolojik Temelli Bilimsel Araştırma Projesi (BAP), Yayınlanmamış Rapor (Proje No: 2014/151078), Ankara, Türkiye.

Tübives (2020) Taxa In Provinces, http://www.tubisev.com/.

Türkmen N, Düzenli A (1998) The Flora of Dörtyol and Erzin Districts of Hatay Province in Turkey, Tubitak Tr. J. of Botany, 22:121-141.

Vural M (2006) Türkiye'nin Kırmı Liste Taslağı,http://portal.milliparklar.gov.tr.

Yolcu H (1998) Kuseyr (Habibin Neccar) Dağları (Hatay) Florası Üzerinde Bir Araştırma. Mustafa Kemal Üniversitesi Fen Bilimleri Enstitüsü Biyoloji Anabilim Dalı, Yüksek Lisans Tezi, Hatay, 59 s. 